\title{
PARTIDOS POLÍTICOS E ESPECTRO IDEOLÓGICO: PARLAMENTARES, ESPECIALISTAS, ESQUERDA E DIREITA NO BRASIL ${ }^{12}$
}

\author{
Ana Paula Brito Maciel ${ }^{3}$ \\ Anderson de Oliveira Alarcon ${ }^{4}$ \\ Éder Rodrigo Gimenes ${ }^{5}$
}

\begin{abstract}
RESUMO
Este artigo visa contribuir com o debate sobre a localização ideológica dos partidos políticos brasileiros. Sendo o Brasil uma democracia recente com alta fragmentação partidária e inconsistências ideológicas, está presente no discurso do senso comum a ideia de que os partidos se limitam ao pragmatismo eleitoral. Para aferir essa percepção, analisamos como os parlamentares do legislativo federal dos principais partidos brasileiros se autoposicionam numa escala esquerda-direita, com base no levantamento realizado pela Pesquisa Legislativa Brasileira (PLB) em 2013 e em dados levantados por experts surveys - já comparados por Tarouco e Madeira (2015). A análise comparativa entre os resultados da classificação no espectro político nos indica que há um reconhecimento de diferenças ideológicas, tanto pelos especialistas quanto pelos parlamentares, apresentando-se uma ordenação coerente na classificação dos partidos políticos na escala esquerda-centro-direita. Além de tal constatação, sugerimos que é pertinente o desenvolvimento de uma agenda de pesquisas nos próximos anos acerca do tema que possa incluir partidos que não foram contemplados pelos bancos de dados.
\end{abstract}

Palavras-chave: Partidos políticos. Espectro ideológico. Parlamentares. Brasil.

\begin{abstract}
This article aims to contribute to the debate on the ideological location of Brazilian political parties. Since Brazil is a recent democracy with high partisan fragmentation and ideological inconsistencies, it is present in the common sense discourse the idea that the parties are limited to electoral pragmatism. To assess this perception, we analyze how the parliamentarians of the federal legislature of the main Brazilian parties position themselves on a left-right scale, based on the survey conducted by the Brazilian Legislative Survey in 2013 and on the data collected by expert surveys - already compared by Tarouco and Madeira (2015). The comparative analysis between the results of the classification in the political spectrum indicates us that there is a recognition of ideological differences, both by the specialists and the parliamentarians, presenting a coherent ordering in the classification of political parties in the left-center-right scale. In addition to this, we suggest that it is pertinent to develop a research agenda in the coming years on the subject that could include parties that were not covered by the databases.
\end{abstract}

Keywords: Political parties. Ideological spectrum. Parliamentarians. Brazil.

\section{RESUMEN}

Este artículo pretende contribuir con el debate sobre la ubicación ideológica de los partidos políticos brasileños. Siendo Brasil una democracia reciente con alta fragmentación partidista y inconsistencias ideológicas, está presente en el discurso del sentido común la idea de que los partidos se limitan al pragmatismo electoral. Para medir esta percepción, analizamos cómo los parlamentarios del legislativo federal de los principales partidos brasileños se autoposicionan en una escala izquierda-derecha, con base en el levantamiento realizado por la Pesquisa Legislativa Brasileira en 2013 y en los datos recogidos por experts surveys - en comparación de Tarouco e Madeira (2015). El análisis comparativo entre los resultados de la clasificación en el espectro político nos indica que hay un reconocimiento de diferencias ideológicas, tanto por los especialistas cuanto por los parlamentarios,

\footnotetext{
${ }^{1}$ Submetido em: 25 de Agosto de 2017. Aprovado em: 22 de setembro de 2017.

${ }^{2}$ DOI: http://dx.doi.org/10.5380/recp.v8i3.54834

${ }^{3}$ Mestranda em Ciências Sociais pela Universidade Estadual de Maringá (UEM). Bacharela e licenciada em Ciências Sociais também pela Universidade Estadual de Maringá. E-mail: anapaulajrn@ hotmail.com.

${ }^{4}$ Mestrando em Ciências Sociais pela Universidade Estadual de Maringá (UEM). Especialista em Direito Público pela Faculdade Processus. Especialista em Curso Internacional de Derecho Eleitoral pela Facultad de Estudios Superiores Aragón. Graduado em Direito pela Universidade Estadual de Maringá. E-mail: contato@andersonalarcon.com.

${ }^{5}$ Doutor em Sociologia Política pela Universidade Federal de Santa Catarina (UFSC). Mestre em Ciências Sociais pela Universidade Estadual de Maringá (UEM). E-mail: ergimenes@uem.br.
} 
MACIEL, A. P. B. ALARCON, A. O. \& GIMENES, E. R. Partidos políticos e espectro ideológico: parlamentares, especialistas, esquerda e direita no Brasil

presentando una ordenación coherente en la clasificación de los partidos políticos en la escala izquierda-centroderecha. Además de tal constatación, sugerimos que es pertinente el desarrollo de una agenda de investigaciones en los próximos años sobre el tema que pueda incluir partidos que no fueron contemplados por los bancos de datos.

Palabras clave: Partidos políticos. Espectro ideológico. Parlamentares. Brasil.

\section{CONSIDERAÇÕES INICIAIS}

O Brasil vive um recente processo de redemocratização desde a abertura política após o regime militar, dispondo hoje de um sistema multipartidário altamente fragmentado, com trinta e cinco partidos políticos registrados no Tribunal Superior Eleitoral (TSE) e sessenta e três em processo de formação (BRASIL, 2017).

No que tange ao eleitorado, estudos de opinião pública apontam que a maior parte dos eleitores dispõe de baixa sofisticação política e cognitiva, o que dificulta o estabelecimento de laços partidários (GIMENES et al., 2016) e mesmo a utilização das legendas como atalhos para o posicionamento da população na política de modo geral e no momento eleitoral, aos moldes do modelo da escolha racional (DOWNS, 1957).

Assim como ocorre no contexto internacional (DASSONNEVILLE; HOOGHE, 2016), também entre os brasileiros foi constatada a dificuldade em diferenciar os partidos que protagonizam as disputas presidenciais desde 1994, o Partido dos Trabalhadores (PT) e o Partido da Social Democracia Brasileiro (PSDB): Ribeiro et al. (2017) verificaram, a partir de dados do Estudo Eleitoral Brasileiro (ESEB) referentes aos períodos pós eleitorais de 2002, 2006, 2010 e 2014, a dificuldade dos eleitores em diferenciar tais legendas, sendo que a indiferenciação é maior em períodos de crise política.

De acordo com Carreirão (2014), o Brasil é o país mais fragmentado quando se trata de legendas partidárias, e a tendência é se fragmentar cada vez mais. A grande quantidade de partidos não significa que o apoio eleitoral é plural. O que se constata é que o grande volume de legendas dificulta o conhecimento dos eleitores sobre elas, gerando problemas de accountability, com repercussões sobre a qualidade da representação. De acordo com Moisés e Carneiro (2015), nas palavras de Gimenes (2017):

[As legendas] encontram-se pouco enraizadas junto ao eleitorado, o que demonstra a fragilidade no atendimento das expectativas dos eleitores com relação à representação". O alto grau de fragmentação partidária do nosso sistema dificulta que o eleitorado se identifique com grande parte das organizações partidárias, "tanto por conta do elevado número de partidos existentes quanto pelas diversas coligações e coalizões estabelecidas pelas legendas e da recorrência de apresentação de propostas semelhantes. 
Deve-se considerar outros fatores que dificultam o desenvolvimento dos laços dos eleitores com partidos políticos no Brasil. Gimenes (2017) destaca alguns pontos que assinalam a conjuntura do baixo grau de institucionalização das legendas partidárias, tais como o personalismo político, a desconfiança do eleitorado com relação aos partidos, a alta volatilidade eleitoral, a migração partidária, a fragilidade dos partidos, a ineficácia das instituições políticas, os clãs regionais e famílias no poder, as denúncias de corrupção e a proximidade dos programas partidários. A complexa estrutura institucional dificultaria o fortalecimento dos partidos políticos, enquanto sua alta fragmentação e pluralismo gerariam dificuldade entre os eleitores para reconhecerem e se afeiçoarem aos partidos políticos, de modo que haveriam causas individuais e contextuais que explicariam o baixo partidarismo no país.

Por um lado, há críticas à conformação de coligações e coalizões de governo, inclusive distintas nas diferentes esferas do poder, as quais tornam mais difícil aos eleitores a percepção de qual partido defende quais bandeiras. Por outro lado, a despeito da afirmação de Singer (2000) de que o posicionamento ideológico faria sentido para os eleitores, a tese de Carreirão (2002) é de que a escolarização influiria na capacidade dos indivíduos de localizar os partidos no espectro entre "esquerda" e "direita". Porém, o percentual de eleitores altamente escolarizados segue baixo no país, assim como daqueles que podem ser considerados mobilizados cognitivamente (GIMENES, 2015).

A dificuldade por parte do eleitorado em diferenciar os partidos tornou-se especialmente latente a partir da onda de protestos e manifestações de rua ocorridos em junho de 2013, quando, em momento posterior e por razões distintas daquelas que iniciaram as mobilizações, uma parcela dos manifestantes passou a disseminar o discurso apartidário, que evoluiu para a materialização por meio de ações violentas até o antipartidarismo (SINGER, 2013).

Ainda que verifiquemos entre os brasileiros o fortalecimento do antipetismo em maior medida do que os sentimentos negativos por outros partidos (SAMUELS; ZUCCO JUNIOR, 2014; RIBEIRO; CARREIRÃO; BORBA, 2016; PAIVA; KRAUSE; LAMEIRÃO, 2016), após a redução generalizada da identificação partidária decorrente do escândalo de corrupção do mensalão em 2005, que afetou principalmente o Partido dos Trabalhadores (ocupante da presidência da República à época), foi o próprio PT a legenda que mais cresceu nos anos seguintes (BORBA; GIMENES; RIBEIRO, 2015; GIMENES et al., 2016), de modo que após a crise política e econômica que permeou o início do segundo mandato presidencial de Dilma Rousseff (PT) e culminou em seu impeachment, pesquisas de opinião pública recentes apontam a retomada do crescimento da identificação com o referido partido. 
MACIEL, A. P. B. ALARCON, A. O. \& GIMENES, E. R. Partidos políticos e espectro ideológico: parlamentares, especialistas, esquerda e direita no Brasil

Considerando-se o contexto deste debate entre os estudos culturalistas, buscamos, neste artigo, compreender como atores políticos específicos percebem a localização dos partidos no espectro ideológico. Para tanto, utilizamos dados da Pesquisa Legislativa Brasileira (PLB) coletados em 2013, referentes aos parlamentares da 54 legislatura (2011-2014), e de experts surveys ${ }^{6}$, com o objetivo de constatar se, diferentemente do verificado entre a população, há, por parte da elite política legislativa, clareza com relação ao posicionamento dos partidos políticos em uma escala "esquerda-direita".

Diante do exposto, além desta seção introdutória, este artigo é composto ainda por outras quatro seções. Na próxima, apresentamos considerações sobre a ideia de "ideologia" e a composição do sistema partidário brasileiro. Na terceira seção, expomos resultados de experts surveys realizados em 2007 e 2010, sistematizados por Tarouco e Madeira (2015). A quarta seção trata dos resultados da Pesquisa Legislativa Brasileira, quando discutimos a distribuição dos partidos no espectro ideológico a partir do autolocalização dos parlamentares. Por fim, a última seção apresenta reflexões sobre nossa análise, bem como limitações e proposições à agenda de pesquisas sobre o tema.

\section{IDEOLOGIA E SISTEMA PARTIDÁRIO BRASILEIRO}

O espectro ideológico classifica diferentes posições políticas entre dois polos que se distinguem: a esquerda e a direita. O conceito de "ideologia" é complexo e varia conforme o tempo e a conjuntura histórico-cultural, podendo representar um "conjunto de ideias e valores respeitantes à ordem pública e tendo como função orientar os comportamentos políticos coletivos" (SCHEEFFER, 2016, p. 35). Contemplando-se nosso objeto de análise, o conceito fica aqui entendido como sinônimo de "ideologia política", sendo uma arena de disputa entre diferentes projetos que serve como norte para o campo político.

Os termos "direita" e "esquerda" surgiram no contexto da Revolução Francesa (1789) para indicar posicionamentos políticos, quando a esquerda priorizava o igualitarismo e a direita, a aristocracia. Aos poucos os termos foram associados ao liberalismo e conservadorismo. De acordo com Bobbio (1997), a esquerda prioriza a igualdade e a direita, a liberdade; porém, são

\footnotetext{
${ }^{6}$ As avaliações por especialistas foram coletadas pelos chamados experts surveys, nos quais cientistas políticos e/ou especialistas da área foram consultados para classificarem os partidos políticos em escalas elaboradas pelos pesquisadores.
} 
definições que variam conforme o contexto e a conjuntura em que se inserem, permeando hoje o debate pós-materialista ${ }^{7}$, que não se limita apenas às questões econômicas.

Conforme Heywood (2010) argumenta, existem as ideologias "clássicas" e as "novas" ideologias. As primeiras seriam o liberalismo, conservadorismo, socialismo, nacionalismo, anarquismo e fascismo, enquanto as segundas corresponderiam a movimentos como o feminismo, ecologismo, fundamentalismo religioso e multiculturalismo. Sobre o segundo conjunto, que remete a preocupações de ordem pós-material, o autor pondera que são chamadas de "novas" por conferirem notoriedade a certas áreas de debate ideológico anteriormente desconsideradas e por fomentarem o surgimento de perspectivas ideológicas novas e contestadoras.

Nas sociedades pós-industriais, a luta por subsistência material se tornou menos premente para uma proporção cada vez maior da população, cujos indivíduos manifestam mais interesse por qualidade de vida e questões pós-materiais, de modo que as "novas" ideologias diriam respeito a interesses relacionados mais à cultura do que à economia — ou seja, estariam focadas em valores, crenças e estilos de vida (HEYWOOD, 2010).

No caso brasileiro, desde a retomada do multipartidarismo no fim da década de 1970 houve a criação e extinção de dezenas de partidos, assim como muitas das legendas atualmente em funcionamento sofreram alterações de nomenclatura ou foram extintas para a criação de novas, com a mesma base (GIMENES, 2017). O país atende pelo maior número efetivo de partidos ocupantes do Poder Legislativo no mundo (GALLAGHER, 2015), o que, em conjunto com a articulação governativa por meio do presidencialismo de coalizão (LIMONGI, 2006), dificulta a distribuição dos partidos no espectro ideológico.

Tarouco e Madeira (2013), pesquisadores dedicados a tal intento, observam que é necessário considerar os paradoxos da conjuntura política, social e econômica para construir uma escala de valores entre esquerda e direita no Brasil. Nesse sentido, é importante retomarmos aspectos da construção do sistema partidário atual, cujas raízes remontam ao fim de nosso período democrático anterior (1945-1964).

Com a instauração do regime militar no Brasil, o sistema pluripartidário foi substituído pelo bipartidarismo, de modo que, por conseguinte, todos os partidos políticos até então existentes foram extintos com o Ato Institucional 2 (AI-2). À época, era possível a criação de

\footnotetext{
${ }^{7}$ De acordo com Inglehart (2001), o desenvolvimento econômico característico de sociedades avançadas ou pósindustriais, a partir da metade do século XX, tem impulsionado o desenvolvimento de valores pós-materialistas. Essa mudança valorativa teria promovido alterações no sistema de normas que impactam diretamente em relações de gênero, normais sexuais, no campo religioso e no comportamento político.
} 
MACIEL, A. P. B. ALARCON, A. O. \& GIMENES, E. R. Partidos políticos e espectro ideológico: parlamentares, especialistas, esquerda e direita no Brasil

novos partidos, porém as regras impostas dificultavam tal ação ${ }^{8}$, sendo que apenas dois partidos atenderam aos requisitos para constituição: a Aliança Renovadora Nacional (Arena) e o Movimento Democrático Brasileiro (MDB). Assim, o sistema bipartidário persistiu no Brasil entre 1966 e 1979.

De acordo com Fleischer (2007), quando o governo percebeu que o partido de oposição ao militarismo - o MDB - estava se fortificando com o eleitorado, o que dificultaria a manutenção da Arena como dominante no Congresso, surgiu a necessidade de um realinhamento partidário, o que se deu pela extinção dos partidos existentes (Lei Orgânica dos Partidos Políticos, n 6767, aprovada em 22 de novembro de 1979). Tal extinção foi sucedida pela possibilidade de instauração do pluripartidarismo moderado, quando 5 (cinco) legendas foram constituídas: Partido Democrático Social (PDS), sucessor da Arena; Partido do Movimento Democrático Brasileiro (PMDB), sucessor do MDB; Partido Popular (PP); Partido Democrático Trabalhista (PDT); e o Partido dos Trabalhadores (PT).

Tal sistema foi moderado apenas nos primeiros anos de aplicação, sendo que em 1985 a criação de novas legendas se tornou mais simples, com a alteração da Constituição Federal consequente do retorno dos governos civis. Nesse contexto, em 1991 havia mais de quarenta partidos registrados junto ao TSE, de modo que desde a primeira década pós-redemocratização o sistema partidário se caracterizou por uma alta fragmentação, combinada com a ausência de maiorias parlamentares unipartidárias.

Nicolau (1996) ressalta que a singularidade da democracia brasileira consiste no grande número de partidos políticos que foram criados por cidadãos anônimos após a abertura política, muitos sem relevância eleitoral. Tal peculiaridade seria consequência da combinação de aspectos comportamentais e institucionais, como o comportamento do eleitorado e dos dirigentes partidários e as regras dos sistemas partidário, eleitoral e político brasileiros.

A despeito da possibilidade de um sistema composto por uma grande quantidade de partidos políticos resultar em considerável indiferenciação entre as legendas, estudos recentes apontam a necessidade de relativização da noção de homogeneização dos partidos, como apontam os resultados de Scheeffer (2016) e Ribeiro e Bolognesi (2017), por exemplo.

\footnotetext{
${ }^{8}$ Foi decretado o Ato Institucional 2, de 27 de outubro de 1965, art. 18: "Ficam extintos os atuais Partidos Políticos e cancelados os respectivos registros. Parágrafo único - Para a organização dos novos Partidos são mantidas as exigências da Lei $n^{\circ}$ 4.740, de 15 de julho de 1965, e suas modificações". As dificuldades para a criação de novos partidos ocorreram devido aos pré-requisitos que passaram a ser exigidos no Ato Complementar 4 , de 20 de novembro de 1965, tal como no art. $1^{\circ}$ : “Aos membros efetivos do Congresso Nacional, em número não inferior a 120 deputados e 20 senadores, caberá a iniciativa de promover a criação, dentro do prazo de 45 dias, de organizações que terão, nos termos do presente Ato, atribuições de partidos políticos enquanto estes não se constituírem."
} 
O primeiro estudo testou a hipótese de os conceitos ideológicos abarcados pela escala esquerda-centro-direita terem aplicabilidade e de ainda fazerem sentido para os partidos políticos brasileiros, adversando a concepção de que não há diferenciação. Para tanto, Scheeffer (2016) verificou o quão compatíveis foram os votos nominais dos parlamentares na Câmara dos Deputados no período correspondente ao Governo Dilma (2011- 2015) com o campo ideológico em que seus respectivos partidos estão localizados. Com isso, o autor identificou que o teor ideológico prevalece, de maneira que os partidos se posicionam coerentemente. Ainda, as diferenças entre esquerda e direita estão além dos velhos temas que envolvem maior ou menor intervenção do Estado sobre as perspectivas social e econômica, de modo que, em suma, o autor alega que ainda faz sentido considerarmos a classificação ideológica dos partidos políticos.

Já o estudo de Ribeiro e Bolognesi (2017) se debruçou sobre o legislativo municipal do estado de Santa Catarina, com foco na análise da relação entre valores e posicionamentos ideológicos de vereadores com relação a determinados temas e de como posicionavam seus partidos a esse respeito. Os autores verificaram até que ponto tais atores políticos se diferenciam ideologicamente de acordo com suas vinculações partidárias e concluíram que existe coerência entre o autoposicionamento ideológico manifestado pelos vereadores e a maneira como posicionam seus partidos. Para indicadores de participação política haveria maior diferenciação, enquanto com relação ao estatismo o consenso entre os legisladores municipais se manifesta pela importância atribuída ao Estado. Todavia, os resultados apontam que a hipótese de indiferenciação ideológica não se confirmaria também no cenário local.

Diante de tais resultados, nos debruçamos, na próxima seção, no diálogo entre resultados de pesquisas com cientistas políticos - experts com relação à classificação dos partidos políticos brasileiros no espectro ideológico, sob a perspectiva acadêmica - e os posicionamentos indicados pelos parlamentares brasileiros em survey específico.

\section{PARTIDOS POLÍTICOS E ESPECTRO IDEOLÓGICO NO BRASIL: A OPINIÃO DE EXPERTS}

Tarouco e Madeira (2015) destacam a importância da dimensão ideológica na análise de partidos políticos brasileiros, de modo que investigaram, a partir de surveys aplicados à especialistas - aos quais foi solicitada a classificação das legendas nacionais em escalas elaboradas pelos pesquisadores - a hipótese de que os partidos em geral não têm ideologia definida. 
MACIEL, A. P. B. ALARCON, A. O. \& GIMENES, E. R. Partidos políticos e espectro ideológico: parlamentares, especialistas, esquerda e direita no Brasil

Sobre tal estudo, é importante reconhecer que existe uma limitação do método de avaliação com especialistas, chamados de experts surveys, uma vez que são aplicados em contextos específicos e que estão sujeitos a julgamentos individuais e a uma polarização "artificial", pois alguns respondentes podem buscar "preencher" toda a escala ideológica. Entretanto, apesar das críticas, Tarouco e Madeira (2015) consideram o método adequado, uma vez que se trata do julgamento por especialistas que são referência acerca do conhecimento científico desenvolvido na área.

Nesse sentido, os autores comparam os resultados de dois experts surveys desenvolvidos em 2007 e 2010. O primeiro refere-se ao projeto desenvolvido por Wiesehomeier e Benoit (2007), que enviaram questionários pela internet, no ano anterior, a especialistas brasileiros, para que os mesmos classificassem os partidos políticos em uma escala de 20 pontos entre esquerda e direita, onde 1 correspondia a esquerda e 20 a direita.

A segunda coleta de dados ocorreu quando da realização do encontro da Associação Brasileira de Ciência Política (ABCP) de 2010, em que os pesquisadores das áreas temáticas relacionadas a eleições, representação política e instituições foram convidados a classificar os partidos políticos brasileiros no espectro esquerda-direita. A escala era de 7 pontos, sendo que 1 correspondia à extrema esquerda e 7 à extrema direita.

Sobre os resultados, destacamos inicialmente que mesmo entre especialistas houve dificuldade de classificação de parte dos partidos no espectro ideológico, o que implica inferirmos que, ainda que para uma parcela composta por legendas com menor representatividade no Legislativo, não é clara a possibilidade de diferenciação ou de classificação de todos os mais de trinta partidos brasileiros, mesmo por parte de especialistas.

Com relação às respostas, expomos na tabela abaixo as médias atingidas pelos partidos políticos segundo os dois conjuntos de especialistas, sendo que a escala de Wiesehomeier e Benoit (2007) variava entre 1 e 20 pontos e a escala do survey aplicado no encontro da ABCP tinha amplitude de 1 a 7 pontos:

TABELA 1 - POSIÇÕES DOS PARTIDOS POLÍTICOS BRASILEIROS NO ESPECTRO IDEOLÓGICO SEGUNDO RESULTADOS DE EXPERTS SURVEYS

\begin{tabular}{c|c|c}
\hline Partido & $\begin{array}{c}\text { Posição na escala de } \\
\text { Wiesehomeier e Benoit (2007) }\end{array}$ & $\begin{array}{c}\text { Posição na escala do survey ABCP } \\
\mathbf{( 2 0 1 0 )}\end{array}$ \\
\hline PSOL & 2,95 & 1,4 \\
\hline PCdoB & 4,96 & 2,3 \\
\hline PT & 6,37 & 2,9 \\
\hline PSB & 7,5 & 3 \\
\hline
\end{tabular}




\begin{tabular}{c|c|c}
\hline PDT & 8,38 & 3,3 \\
\hline PV & 7,36 & 3,5 \\
\hline PPS & 10,38 & 4 \\
\hline PMDB & 11,5 & 4,2 \\
\hline PSDB & 13,46 & 4,6 \\
\hline PTB & 13,6 & 5 \\
\hline PSC & 15,62 & 5,2 \\
\hline PP & 16,78 & 6 \\
\hline DEM & 17,33 & 6,2 \\
\hline
\end{tabular}

FONTE: Adaptado de TAROUCO; MADEIRA (2015, p. 32).

De modo geral, a comparação dos resultados denota, primeiramente, a distribuição dos partidos políticos elencados em praticamente toda a escala disponibilizada nos experts surveys, uma vez que a amplitude do espectro segundo o questionário de Wiesehomeier e Benoit (2007) foi distribuída entre quase todos os pontos (só não há partidos no primeiro e nos últimos pontos da escala 1-20) e os respondentes do encontro da $\mathrm{ABCP}$ ocuparam praticamente todo o espectro esquerda-direita na escala 1-7 pontos.

Em segundo lugar, verificamos coerência entre as posições atribuídas a todas as legendas nos dois surveys, com exceção do Partido Verde (PV), conforme destacamos na Tabela 1, uma vez que a legenda assume distintas posições nas distribuições nos anos de 2007 e de 2010. Isso pode decorrer, em alguma medida, da alteração da condição do partido nos contextos políticos daqueles anos, especialmente por conta da relevância da candidatura de Marina Silva à presidência da República no ano de aplicação do segundo survey, quando a mesma atingiu o melhor desempenho para o terceiro colocado na disputa majoritária, cristalizada entre PT e PSDB desde $1994^{9}$.

\section{PARTIDOS POLÍTICOS E ESPECTRO IDEOLÓGICO NO BRASIL: A OPINIÃO DOS PARLAMENTARES}

Para além da classificação dos partidos políticos no espectro ideológico por especialistas, faz-se relevante a reflexão sobre como os próprios parlamentares percebem a distribuição das legendas, especialmente daquelas às quais estão filiados, entre esquerda e direita. Para tanto, utilizamos dados da Pesquisa Legislativa Brasileira (PLB), que se trata de

\footnotetext{
${ }^{9}$ No período eleitoral seguinte, Marina Silva atingiu resultado ainda mais expressivo (21,31\% de votos válidos no primeiro turno, contra 19,33\% em 2010), porém concorrendo pelo Partido Socialista Brasileiro (PSB). Uma discussão sobre o impacto do PT, PSDB e de candidaturas por outros partidos às eleições presidenciais encontrase em Gimenes (2017).
} 
MACIEL, A. P. B. ALARCON, A. O. \& GIMENES, E. R. Partidos políticos e espectro ideológico: parlamentares, especialistas, esquerda e direita no Brasil

um projeto de survey iniciado em 1990 por Timothy Power, o qual, atualmente, também conta com a colaboração de César Zucco Junior.

O projeto é replicado entre legisladores de distintos países a cada legislatura, sendo que no caso brasileiro o mapeamento de opiniões, posicionamentos e perspectivas políticas de deputados e senadores completou sua sétima edição em 2013, quando da aplicação referente à legislatura 2011-2014. Este banco de dados, que pode ser considerado o mais completo acerca do pensamento dos parlamentares brasileiros, está disponível ao público no repositório de dados do Instituto para Ciências Sociais Quantitativas da Universidade de Harvard (IQSS) ${ }^{10}$; nos referimos, neste artigo, à última edição do projeto.

Dentre seu conjunto de variáveis, a PLB inclui questões relacionadas à classificação ideológica, com relação às quais os parlamentares se autoposicionam e posicionam todos os principais partidos em uma escala ideológica com amplitude de 1 a 10 pontos. Sobre tal aspecto, Zucco Junior (2011) observa que, de modo sumário, considera-se que cada partido tenha uma posição ideológica "real" que não é observável pelos analistas, pois os legisladores podem interpretar a escala de respostas de maneira distinta dos experts acadêmicos. Nesse sentido, as preferências e o posicionamento declarados pelos próprios parlamentares nos informariam com maior precisão sobre tal distribuição das legendas no espectro ideológico e serviria como base à interpretação de dados a esse respeito. Ademais, a racionalização oferecida pelos próprios congressistas teria um significado notável para a atividade legislativa.

Na PLB de 2013 havia uma questão específica referente ao autoposicionamento dos parlamentares em uma escala, a qual enunciava: "Vamos supor que nesta reta o número 1 corresponda à esquerda, o número 5 ao centro, e o número 10 à direita. Como o(a) Sr.(a) está vendo, uma pessoa que fosse muito de esquerda estaria no número 1, uma muito de direita, no número 10. Onde é que o(a) Sr.(a) se colocaria?". Dentre os consultados, $29,7 \%$ dos legisladores não responderam à questão, indicando alta taxa de abstenção por parte dos parlamentares com relação à identificação ideológica. Não obstante, apresentamos abaixo a distribuição das médias atribuídas pelos parlamentares respondentes de cada um dos principais partidos brasileiros aos seus posicionamentos ideológicos pessoais:

\footnotetext{
${ }^{10}$ Não nos detemos, por conta do objetivo desta pesquisa, no detalhamento sobre a composição do banco e sobre a descrição dos entrevistados. Os dados a esse respeito encontram-se em Universidade de Harvard (2014).
} 
TABELA 2 - MÉDIA DO AUTOPOSICIONAMENTO IDEOLÓGICO DOS PARLAMENTARES POR PARTIDO POLÍTICO

\begin{tabular}{c|c}
\hline Partido político & Média \\
\hline PCdoB & 1,43 \\
\hline PSOL & 2 \\
\hline PT & 2,62 \\
\hline PCB-PPS & 3 \\
\hline PSB & 3,43 \\
\hline PTB & 4 \\
\hline PSDB & 4,1 \\
\hline PDT & 4,5 \\
\hline PL-PRONA-PR & 4,5 \\
\hline PMDB & 4,58 \\
\hline PMN & 5 \\
\hline PRB & 5,33 \\
\hline PDS-PPR-PDC-PPB-PP (2003) & 6 \\
\hline PSC & 6 \\
\hline PSD & 6 \\
\hline PFL-DEM & 6,4 \\
\hline Outros partidos & 6,67 \\
\hline Total & 4,38 \\
\hline
\end{tabular}

FONTE: Pesquisa Legislativa Brasileira (2013).

Destacamos que a distribuição dos partidos no espectro ideológico pelos parlamentares destoa, parcialmente e com relação aos partidos de direita, daquela decorrente das análises de especialistas, no que diz respeito à ocupação do espectro - uma vez que, em média, os parlamentares não classificam seus posicionamentos no espectro mais à direita, sendo que a maior média dentre os partidos foi atingida pelo atual Democratas (DEM), cujo valor de 6,4 pode ser considerado de centro-direita. Por outro lado, uma limitação do questionário diz respeito aos demais partidos, dentre os quais verificamos a existência de parlamentares com posicionamento mais à direita do que daquelas legendas partidárias destacadas na tabela. Contudo, de modo geral, a média indica um posicionamento dos legisladores federais brasileiros no campo de centro-esquerda do espectro ideológico.

Sobre a distribuição dos partidos no espectro sem a ocupação de parcela significativa dos pontos mais à direita, há algumas décadas Pierucci (1987) afirmou que no Brasil existiria uma tendência de receio entre os partidos políticos de direita em se posicionarem como tal, em decorrência da associação entre essa posição e o apoio ao militarismo, de modo que haveria 
MACIEL, A. P. B. ALARCON, A. O. \& GIMENES, E. R. Partidos políticos e espectro ideológico: parlamentares, especialistas, esquerda e direita no Brasil

entre eles a preocupação em se apresentarem como postulantes de posicionamentos centristas. Tal fenômeno comporia o que o autor denominou "direita envergonhada":

No Brasil da transição democrática, para os políticos que dependem da aprovação das urnas, à luz dos cálculos racionais de custos e benefícios certamente não é muito aconselhável confessar-se de direita. Pior ainda de extrema direita [...]. Esta vergonha de si, esta má consciência da direita só faz dificultar os trabalhos de decifração e deslizar a informação. (PIERUCCI, 1987, p. 13).

No que tange aos posicionamentos no centro do espectro, Ribeiro e Bolognesi (2017) corroboram a observação de Pierucci (1987) ao afirmarem, à luz do legislativo municipal catarinense, que o caminho preferido por parte dos políticos e dos eleitores é a adoção do candidato-centrismo, onde as bandeiras partidárias se mesclam em torno do centro ideológico, sem determinação de posicionamentos radicais ou considerados extremos.

Em nosso entendimento, tais aspectos justificariam a média geral do posicionamento dos parlamentares próxima ao centro, com tendência à esquerda. Contudo, há que ser destacado o avanço do discurso relacionado à direita no Brasil atualmente, seja por meio de pautas conservadoras e de posicionamentos radicais, seja por meio da ocupação das ruas por manifestações declaradamente conservadoras, o que pode convergir para alterações na medida sob análise quando da aplicação da próxima edição da $\operatorname{PLB}^{11}$.

\section{DISTRIBUIÇÃO DOS PARTIDOS NO ESPECTRO IDEOLÓGICO: CONSIDERAÇÕES FINAIS OU AGENDA DE PESQUISA?}

Considerado o contexto democrático recente, caracterizado por dificuldades cognitivas do eleitorado em diferenciar partidos e pelo grande número de legendas existentes (e em processo de formalização) no Brasil, são recorrentes os argumentos sobre a indiferenciação dos partidos perante o eleitorado, comprovados empiricamente pelo estudo recente de Borba et al. (2017), bem como a perspectiva de aproximação dos partidos com relação ao centro do espectro, evitando posições extremas (RIBEIRO; BOLOGNESI, 2017).

Diante de tal cenário, buscamos compreender como atores políticos específicos percebem a localização dos partidos no espectro ideológico, pautando-se, mais especificamente, pela opinião de especialistas (cientistas políticos) em comparação à de parlamentares brasileiros, de maneira a confrontar a prospecção que nós, membros da academia, traçamos para

\footnotetext{
${ }^{11}$ Para além do caso brasileiro, destacamos o avanço de partidos de direita tanto entre democracias em processo de fortalecimento quanto naquelas consolidadas.
} 
a distribuição dos partidos políticos no espectro ideológico em confronto com a localização que a elite legislativa dessas legendas entende ser a correta.

Nesse sentido, nesta seção expomos dados que apontam para uma agenda a ser detalhada e acompanhada nos próximos anos (e ondas da PLB), além de propormos considerações finais sobre o tema. Julgamos relevante expor em uma mesma tabela as percepções de experts com aquelas de especialistas, a fim de verificar se tais grupos vislumbram a distribuição dos partidos no espectro ideológico de maneira congruente ou discrepante. Para tanto, unimos os resultados da PLB (Tabela 2) àqueles anteriormente expostos, acerca de experts surveys (Tabela 1), e expomos na tabela abaixo o rol de legendas constantes nas três pesquisas:

TABELA 3 - POSIÇÕES DOS PARTIDOS POLÍTICOS BRASILEIROS NO ESPECTRO IDEOLÓGICO SEGUNDO RESULTADOS DE EXPERTS SURVEYS E DA MÉDIA DO AUTOPOSICIONAMENTO IDEOLÓGICO DOS PARLAMENTARES

\begin{tabular}{c|c|c|c}
\hline Partido & $\begin{array}{c}\text { Posição na escala de } \\
\text { Wiesehomeier e Benoit } \\
(\mathbf{2 0 0 7 )}\end{array}$ & $\begin{array}{c}\text { Posição na escala do } \\
\text { survey ABCP (2010) }\end{array}$ & PLB (2013) \\
\hline PSOL & 2,95 & 1,4 & 2 \\
\hline PCdoB & 4,96 & 2,3 & 1,43 \\
\hline PT & 6,37 & 2,9 & 2,62 \\
\hline PSB & 7,5 & 3 & 3,43 \\
\hline PDT & 8,38 & 3,3 & 4,5 \\
\hline PCB-PPS & 10,38 & 4 & 3 \\
\hline PMDB & 11,5 & 4,2 & 4,58 \\
\hline PSDB & 13,46 & 4,6 & 4,1 \\
\hline PTB & 13,6 & 5 & 6 \\
\hline PSC & 15,62 & 5,2 & 6 \\
\hline PP & 16,78 & 6 & 6,4 \\
\hline DEM & 17,33 & 6,2 & 6 \\
\hline
\end{tabular}

FONTE: Adaptado de Tarouco e Madeira (2015, p. 32) e Pesquisa Legislativa Brasileira (2013).

Ao considerarmos os resultados dos três surveys em conjunto podemos postular a existência de três blocos de partidos, sendo aqui considerados os posicionamentos mencionados e não necessariamente aspectos ideológicos de fato. Em primeiro lugar, verificamos um agrupamento de partidos cuja localização no campo da esquerda é percebida por especialistas e se repete quando do autoposicionamento dos parlamentares. Dentre tais partidos, verificamos posições próximas à extrema esquerda no Partido Socialismo e Liberdade (PSOL) e no Partido Comunista do Brasil (PCdoB) - sendo que os parlamentares do segundo se posicionam de 
MACIEL, A. P. B. ALARCON, A. O. \& GIMENES, E. R. Partidos políticos e espectro ideológico: parlamentares, especialistas, esquerda e direita no Brasil

maneira mais latente à esquerda do que aqueles do primeiro, em dissonância com a percepção dos experts - e o posicionamento claro do PT à esquerda tanto entre especialistas quanto por seus parlamentares. Já nos casos do PSB e do Partido Democrático Trabalhista (PDT), as médias estão mais próximas dos pontos médios das escalas, de modo que podem ser considerados partidos de centro-esquerda.

Dentre o segundo conjunto de partidos, a maioria das legendas recebeu realce por conta da incongruência na sua ordenação no espectro pelos diferentes respondentes dos surveys. Enquanto os especialistas atribuíram posições que confirmariam o Partido Popular Socialista (PPS), o PSDB e o Partido Trabalhista Brasileiro (PTB) como legendas de centro-direita, seus parlamentares indicaram posicionamentos mais à esquerda, no primeiro caso, e de centroesquerda para os demais partidos.

Dentre esse conjunto de partidos, destacamos o Partido do Movimento Democrático Brasileiro (PMDB), cuja posição de centro se consolida por meio dos dados analisados: enquanto ambos os conjuntos de especialistas acomodam tal legenda ligeiramente à direita, seus parlamentares se posicionam minimamente à esquerda da escala, de modo que a posição de centro do partido nos parece evidente.

Por fim, o último conjunto de partidos é claramente aquele mais coerente em termos de posicionamento no espectro ideológico: o Partido Social Cristão (PSC), o Partido Progressista (PP) e o DEM são identificados como partidos de direita por ambos os conjuntos de especialistas consultados, ao passo que seus parlamentares assumem posicionamentos de centro-direita, o que, em alguma medida, pode decorrer do fenômeno da "direita envergonhada" (PIERUCCI, 1987) — a qual, se considerados os avanços nos discursos, pautas e manifestações neste âmbito do espectro, tende a ser suplantada por uma "direita orgulhosa".

Diante do exposto, podemos inferir que, a despeito dos distintos surveys empreendidos, com diferentes posicionamentos a respeito do sistema partidário brasileiro, existe relativa ordenação dos partidos políticos no espectro esquerda-direita, uma vez que identificamos a pertinência de agrupamentos de legendas à esquerda, no centro e à direita, a despeito de tais resultados decorrerem de análises baseadas em escalas diferentes.

Contudo, para além desta conclusão, julgamos pertinente refletir sobre os limites impostos pela fragilidade metodológica existente em tal comparação, uma vez que não há dados suficientes para tratarmos de diferenças de médias ou realizarmos testes estatísticos, mas apenas os róis de partidos distribuídos conforme as médias de posicionamento nas diferentes escalas ideológicas. 
Ademais, um segundo aspecto a ser exposto - e este seria o principal ponto em que, em nosso entendimento, as pesquisas precisariam avançar — é a capacidade de expansão desta discussão para além do conjunto de partidos analisados, uma vez que, a despeito de serem consideradas as maiores legendas, mais tradicionais ou que se destacam por posições próximas à extrema esquerda, um amplo rol de partidos não está contemplado nos levantamentos realizados até o momento. Assim, o avanço na agenda de pesquisas sobre o tema depende, em alguma medida, da inclusão destes outros partidos, pois a ampliação do sistema partidário recente aponta que não tratamos necessariamente de novas opções em termos de oferta de candidatos, mas de migrações de partidários que buscam se tornar lideranças em novas legendas. Tal fato não configuraria, em sentido prático, a expansão das ofertas em termos de possibilidades de encaminhamento de demandas. propostas e defesa de direitos, mas a dissolução ou replicação de atores e pautas, o que contribuiria para a elevação da dificuldade dos eleitores em diferenciar partidos e políticos no Brasil.

\section{REFERÊNCIAS}

BOBBIO, N. Igualdade e liberdade. Tradução de: COUTINHO, N. 3. ed. Rio de Janeiro: Ediouro, 1997.

BORBA, J.; GIMENES, E. R.; RIBEIRO, E. A. Bases sociais, atitudinais e comportamentais do apartidarismo brasileiro. Revista Novos Estudos - CEBRAP, São Paulo, n. 101, p. 27-55, mar. 2015.

BRASIL. Ato Complementar No 4, de 20 de Novembro de 1965. Brasília. Disponível em: $<$ http://www2.camara.leg.br/legin/fed/atocom/1960-1969/atocomplementar-4-20-novembro1965-351199-publicacaooriginal-1-pe.html>. Acesso em: 20 ago. 2017.

BRASIL. Ato Institucional $\mathrm{N}^{\mathrm{o}} 2$, de 27 de Outubro de 1965. Brasília. Disponível em: <http://www.planalto.gov.br/ccivil_03/ait/ait-02-65.htm>. Acesso em: 20 ago. 2017.

BRASIL. Lei Orgânica dos Partidos Políticos, nº 6.767, de 20 de Dezembro de 1979. Brasília. Disponível em: <http://www2.camara.leg.br/legin/fed/lei/1970-1979/lei-6767-20-dezembro1979-357280-publicacaooriginal-1-pl.html>. Acesso em: 20 ago. 2017.

BRASIL. Tribunal Superior Eleitoral. Partidos políticos registrados no TSE. Disponível em: $<$ http://www.tse.jus.br/partidos/partidos-politicos/registrados-no-tse>. Acesso em: 16 ago. 2017.

CARREIRÃO, Y. de S. A decisão do voto nas eleições presidenciais brasileiras. Florianópolis: Editora da UFSC; Rio de Janeiro: FGV Editora, 2002.

O sistema partidário brasileiro: um debate com a literatura recente. Revista Brasileira de Ciência Política, Brasília, n. 14, p. 255-295, 2014. 
MACIEL, A. P. B. ALARCON, A. O. \& GIMENES, E. R. Partidos políticos e espectro ideológico: parlamentares, especialistas, esquerda e direita no Brasil

DASSONNEVILLE, R.; HOOGHE, M. Indifference and Alienation: Diverging Dimensions of Electoral Dealignment in Europe. Acta Politica, n. 52, p. 1-23, 2016.

DOWNS, A. An Economic Theory of Democracy. Nova York: Harper Row, 1957.

FLEISCHER, D. Os partidos políticos. In: AVELAR, L.; CINTRA, A. O. (Org.). Sistema político brasileiro: uma introdução. 2. ed. Rio de Janeiro: Konrad Adenauer Stiftung; São Paulo: Editora Unesp, 2007.

GALLAGHER, M. Election Indices. Disponível em: $<$ http://www.tcd.ie/Political_Science/staff/michael_gallagher/ElSystems/Docts/ElectionIndice s.pdf>. Acesso em: 23 abr. 2015.

GIMENES, É. R. A relação dos eleitores com partidos políticos em novas democracias: partidarismo na América Latina. 240 f. Tese (Doutorado em Sociologia Política) - Programa de Pós-Graduação em Sociologia Política, Universidade Federal de Santa Catarina, Florianópolis, 2015.

GIMENES, É. R. et al. Partidarismo no Brasil: análise longitudinal dos condicionantes da identificação partidária (2002-2014). Revista Debates, v. 10, n. 2, p. 121-148, 2016.

GIMENES, É. R. Partidarismo, mobilização cognitiva e participação política no Brasil. In: MARTELLI, C. C. G.; JARDIM, M. C.; GIMENES, É. R. Participação política e democracia no Brasil contemporâneo. Araraquara: Universidade Estadual Júlio de Mesquita Filho, 2017. No prelo.

HEYWOOD, A. Ideologias políticas: do feminismo ao multiculturalismo. Tradução de: MARCOANTONIO, J.; JANIKIAN, M. 1. ed. São Paulo: Ática, 2010. 2 v.

INGLEHART, R. Modernización y posmodernización: el cambio cultural, econômico y político em 43 sociedades. Madrid: Centro de Investigaciones Sociológicas:Siglo Veintuino, 2001.

LIMONGI, F. Presidencialismo e governo de coalizão. In. AVRITZER, L.; ANASTASIA, F. (Org.). Reforma política no Brasil. Belo Horizonte: UFMG, 2006. p. 237-257.

MOISÉS, J. A.; CARNEIRO, G. P. Sobre o enraizamento dos partidos políticos brasileiros. Interesse Nacional, São Paulo, n. 28, p. 20-37, 2015.

NICOLAU, J. M. Multipartidarismo e democracia: um estudo sobre sistema partidário brasileiro. Rio de Janeiro: FGV Editora, 1996.

PAIVA, D.; KRAUSE, S.; LAMEIRÃO, A. P. O eleitor antipetista: partidarismo e avaliação retrospectiva. Revista Opinião Pública, Campinas, v. 22, n. 3, p. 638-674, 2016.

PESQUISA Legislativa Brasileira [Data set]. Instituto para Ciências Sociais Quantitativas da Universidade de Harvard. 2013. Disponível em: https://dataverse.harvard.edu/dataset.xhtml?persistentld=hdl:1902.1/14970. Acesso em 23 abr. 2017. 
PIERUCCI, A. F. As bases da nova direita. Revista Novos Estudos - CEBRAP, São Paulo, v. 19, p. 26-45, 1987.

RIBEIRO, E. A.; CARREIRÃO, Y. de S.; BORBA, J. Sentimentos partidários e antipetismo: condicionantes e covariantes. Revista Opinião Pública, Campinas, v. 22, n. 3, p. 603-637, 2016.

RIBEIRO, E. A. et al. Desalinhamento partidário no Brasil recente: efeitos sobre o sistema político. Trabalho apresentado no 9. Congreso Latinoamericano de Ciência Política, Montevidéu, 2017,

RIBEIRO, E. A.; BOLOGNESI, B. Ideologia e representação: valores e atitudes de legisladores municipais. 2017. No prelo.

SAMUELS, D.; ZUCCO JUNIOR, C. Lulismo, Petismo and the Future of Brazilian Politics. Journal of Politics in Latin America, Hamburgo, v. 6, n. 3, p. 129-158, 2014.

SCHEEFFER, F. Ideologia e comportamento parlamentar na Câmara dos Deputados: faz sentido ainda falar em esquerda e direita? Tese (Doutorado em Sociologia Política)- Programa de Pós-Graduação em Sociologia Política, Universidade Federal de Santa Catarina, Florianópolis, 2016.

SINGER, A. Esquerda e direita no eleitorado brasileiro. São Paulo: Edusp, 2000.

Brasil, junho de 2013: classes e ideologias cruzadas. Revista Novos Estudos CEBRAP, São Paulo, n. 97, p. 23-40, 2013.

TAROUCO, G. da S.; MADEIRA, R. M. Partidos, programas e o debate sobre esquerda e direita no Brasil. Revista de Sociologia e Política, v. 21, n. 45, p. 149-165, 2013.

Os partidos brasileiros segundo seus estudiosos: análise de um expert survey. Revista Civitas, Porto Alegre, v. 15, n. 1, p. e24-e39, 2015.

WIESEHOMEIER, N.; BENOIT, K. Parties and Presidents in Latin America: Data from Expert Surveys in 18 Latin American Countries, 2006-2007 [Data set]. University of Konstanz; Trinity College Dublin, 2007.

ZUCCO JUNIOR, C. Esquerda, direita e governo: a ideologia dos partidos políticos brasileiros. In: POWER, T.; ZUCCO, JUNIOR, C. (Ed.). O Congresso por ele mesmo: autopercepções da classe política brasileira. Belo Horizonte: UFMG, 2011. p. 37-60. 